\title{
Prevalence, impact, and management of depression and anxiety in patients with Parkinson's disease
}

This article was published in the following Dove Press journal:

Journal of Parkinsonism and Restless Legs Syndrome

I April 2016

Number of times this article has been viewed

\author{
Jenna B Renfroe' \\ Travis H Turner ${ }^{2,3}$ \\ Vanessa $\mathrm{K}$ Hinson ${ }^{1,4}$ \\ 'Department of Neurology, Medical \\ University of South Carolina, \\ Charleston, SC, USA; ${ }^{2}$ Mental \\ Health Service, Ralph H. Johnson \\ VA Medical Centre, Charleston, SC, \\ USA; ${ }^{3}$ Department of Psychiatry \\ and Behavioral Sciences, Medical \\ University of South Carolina, \\ Charleston, SC, USA; ${ }^{4}$ Neurology \\ Service, Ralph H. Johnson VA Medical \\ Centre, Charleston, SC, USA
}

\begin{abstract}
Individuals with Parkinson's disease (PD) exhibit higher rates of depression and anxiety than the general and other medically disabled populations. Evidence suggests that mood and anxiety symptoms are related to disease pathology. Rates of depression and anxiety in PD vary depending on how these symptoms are measured, but they are estimated to occur in up to $40 \%$ of patients. These conditions have adverse effects on patient and caregivers' quality of life, level of disability, and mortality, with several studies suggesting greater contribution than motor symptom severity. Pharmacological and psychotherapeutic interventions, particularly in combination, have demonstrated efficacy in treating depression and anxiety in PD. However, additional randomized controlled trials are needed to better delineate when and how to best treat these disabling symptoms.
\end{abstract}

Keywords: Parkinson's disease, depression, anxiety, prevalence, treatment

\section{Introduction}

Parkinson's disease (PD) is most recognized by its cardinal symptoms of tremor, rigidity, bradykinesia, and postural instability. Also common are widespread nonmotor symptoms, including rates of psychiatric symptoms that are disproportionate to both the general population and populations of comparable physical disability. ${ }^{1,2}$ Emotional changes in PD are hypothesized to be related to degradation and disruption of limbic-based basal ganglia circuitry ${ }^{3}$ and dysregulation of other neurotransmitter systems in PD. ${ }^{4}$ In addition, medications used to manage motor symptoms, particularly dopamine agonists, have well-established and fairly common psychiatric side effects, including behavioral disinhibition, visual hallucinations, and psychotic features. This review will focus on mood and anxiety disorders in PD, with the goal of providing PD clinicians and researchers an overview of the impact, prevalence and risk factors, etiology, and empirically supported treatments for mood and anxiety disorders in PD.

\section{Impact}

Numerous studies have shown that depression and anxiety negatively impact selfreport of quality of life in $\mathrm{PD},{ }^{5-11}$ more so than motor symptom severity. ${ }^{7,9}$ One study found that depression has more than twice the impact of motor symptoms on overall health status in PD. ${ }^{12}$ Many studies report comparable effects of depression and anxiety on quality of life, but at least one suggested that anxiety may be the strongest predictor of quality of life in PD. ${ }^{13}$ In addition, psychiatric symptoms contribute significantly to level of caregiver burden and distress. ${ }^{14-16}$ One study found that the greatest predictor
Correspondence: Jenna B Renfroe University of South Carolina, 208 B Rutledge Ave, MSC 108, Charleston, SC 29425-02 I8, USA

Tel +I 8437927262

$\mathrm{Fax}+$ I 843792 |75|

Email renfroe@musc.edu (c) (1) (5) 2016 Renfroe et al. This work is published and licensed by Dove Medical Press Limited. The full terms of this license are available at https://www.dovepress.com/terms. cc) ${ }_{\mathrm{BY}} \mathrm{NC}$ php and incorporate the Creative Commons Attribution - Non Commercial (unported, v3.0) License (http://creativecommons.org/licenses/by-n/3.0/). By accessing the work you hereby accept the Terms. Non-commercial uses of the work are permitted without any further permission from Dove Medical Press Limited, provided the work is properly attributed. For permission for commercial use of this work, please see paragraphs 4.2 and 5 of our Terms (https://www.dovepress.com/terms.php). 
of caregiver-endorsed depressive symptomology on the Geriatric Depression Scale (GDS) was the cared-for patient's GDS score, ${ }^{17}$ suggesting that depressive symptoms in PD patients predict depressive symptoms in their spouses, arguably leading to overall greater health-care burden and cost. Depressive symptomology also leads to greater level of disability in PD. ${ }^{18-21}$ Although some studies have found anxiety to be a significant predictor of health status in PD (measured by the Parkinson Disease Questionnaire ${ }^{22}$ ), depression seems to have a greater impact. ${ }^{12}$ Ravina et $\mathrm{al}^{21}$ demonstrated that depression can lead to earlier treatment of motor symptoms with medication in early PD. In addition, depression has been shown to be an independent predictor of mortality in PD, with a hazard ratio more than two times greater than age. ${ }^{23}$ One study showed a link between depressive symptoms and cardiac dysautonomia in PD patients, which may play a role in depression-related mortality in PD. ${ }^{24}$

\section{Depression}

\section{Prevalence and risk factors}

The prevalence of clinically significant depression in PD ranges from $7 \%$ to $40 \%$, depending on whether strict diagnostic criteria or scores on mood scales are used for classification. ${ }^{25,26}$ Lower prevalence rates are reported when diagnostic status is based on clinical interview and Diagnostic and Statistical Manual of Mental Disorders (DSM) diagnostic criteria are applied, whereas higher prevalence is reported in studies utilizing self-report scales and empirically established cutoffs to obtain depression rate estimates. ${ }^{25}$ The prevalence of PD patients meeting DSM-5 criteria for a major depressive disorder is estimated to be $17 \%$; minor depression (generally characterized as clinically significant depressive symptoms that do not meet DSM criteria for major depression or dysthymia $)^{27}$ is estimated to occur in $22 \%$ of patients, and dysthymia, or persistent low mood for a period of 2 years, is estimated to occur in $13 \%$ of patients. ${ }^{25}$ Estimated prevalence of suicidal ideation in PD is $23 \%$, with estimated rate of completed suicide in PD of $<1 \%-2 \%$, which is not higher than the general older adult population. ${ }^{28-30}$

Depression is common even in early, untreated PD, with an estimated prevalence of $14 \%$ in de novo, or medically untreated patients. ${ }^{31}$ Although no causative relationship is theorized, initiation of antidepressant treatment in older adults is associated with increased incidence of PD within 2 years, ${ }^{32}$ and diagnosis of a major depressive disorder is associated with a 3.2 odds ratio for PD onset within 1 year, ${ }^{33}$ suggesting that depression often predates the onset of clinical motor symptoms.
Risk factors for depression include the akinetic rigid and postural instability/gait difficulty (PIGD) subtype of PD. ${ }^{25,34-36}$ Some studies have found associations between depression and rapid disease progression, ${ }^{18,37,38}$ motor fluctuations, ${ }^{39}$ severity of illness, ${ }^{40}$ younger age of onset, ${ }^{38,39,41}$ and right-sided motor asymmetry. ${ }^{41-43}$ Although some studies show an association between disease severity and depression, ${ }^{9}$ it should be noted that associations between disease severity and depression may relate to the overlap between somatic symptoms of PD and somatic depressive symptomology, often measured by self-report questionnaires like the Beck Depression Inventory. ${ }^{44}$ Another recent study showed that a number of nonmotor factors most strongly predicted presence of depression in PD, including female sex, history of anxiety and/or depression, family history of depression, worse functioning on activities of daily living, and worse cognitive status. ${ }^{45}$

\section{Etiology}

Abundant evidence suggests that PD depression is inherently related to the disease pathology. Clinically, depression often precedes the onset of PD motor symptoms by many years, contradicting the hypothesis that PD depression is simply an adjustment reaction to having a debilitating illness, although this is certainly an additional contributing factor for many individuals. ${ }^{33}$ Some investigators have proposed that depression in PD results from dysfunction of the serotonergic neurotransmitter system. ${ }^{46} \mathrm{PD}$ depression has been related to neuronal loss in the dorsal raphe nuclei, reduced serotonergic binding in basal ganglia and prefrontal cortex, and lower serotonin levels in cerebrospinal fluid. ${ }^{47}$ Others have linked PD depression to dopaminergic dysfunction. The clinical correlate here is that depression and anxiety often worsen in the "off-state," or at the end of dose of the patient's dopaminergic medication. ${ }^{48}$ Findings from both animal ${ }^{49}$ and human studies ${ }^{50}$ have linked depression to impairment of the mesolimbic dopaminergic system and reduced activation of the ventral striatum, ${ }^{51}$ which is affected by PD as the disease progresses. Lastly, there is some evidence to suggest that inflammation may play a role in the pathogenesis of depression in PD, given that increased blood and cerebrospinal fluid markers of inflammation have been related to more severe depression symptoms in PD patients. ${ }^{52,53}$

\section{Treatment}

\section{Pharmacological management}

Despite the prevalence and impact of depression in PD, there is a paucity of well-designed clinical trials for the treatment 
of PD depression. The largest placebo-controlled trial done to date compared the efficacy of paroxetine and venlafaxine XR in 115 patients with PD depression in a multicenter trial. ${ }^{54}$ Based on self-report from the Hamilton Depression Scale (HAM-D), ${ }^{55}$ at week 12 both treatment groups evinced statistically significant improvement over placebo (paroxetine $=6.2$, venlafaxine $=4.2$ ); the difference for paroxetine versus venlafaxine XR was not statistically significant. This is in contrast to results from a study by Menza et al, ${ }^{56}$ comparing the efficacy of nortriptyline to that of paroxetine $\mathrm{XR}$ in 52 patients with PD depression. The treatment effect of nortriptyline was significant for both the overall change in the Hamilton Depression Scale and in the percent responders, whereas paroxetine $\mathrm{CR}$ was not. Both active treatments were well tolerated, but paroxetine $\mathrm{CR}$ had significantly more side effects than placebo and nortriptyline did not. The results of this trial bring up the question whether dual-reuptake inhibitors (acting on both serotonergic and noradrenergic transmission) such as nortriptyline are better suited for PD depression than pure serotonergic agents. Indeed, several small, controlled trials using selective serotonin reuptake inhibitors (SSRIs) failed to show efficacy in PD depression, although a recent meta-analysis showed significant effect of antidepressant treatment on depressive symptoms in PD when SSRI and serotonin-norepinephrine reuptake inhibitors (SNRI) treatment studies were combined. ${ }^{57-59}$

Troeung et $\mathrm{al}^{60}$ recently published a meta-analysis of randomized, placebo-controlled trials for the treatment of anxiety and depression in PD. Of note, this analysis was limited to PD patients who met DSM criteria for depressive or anxiety disorder. Troeung et $\mathrm{al}^{60}$ found that citalopram, nortriptyline, paroxetine, and venlafaxine showed a small, statistically significant treatment effect in reducing depressive symptoms. In this study, the pooled effect size for studies of tricyclic antidepressants (TCAs) was large and significant ( $d=1.35$, $95 \% \mathrm{CI}=0.19-2.52$ ), whereas the pooled effect size for SSRIs was not significant, again suggesting that different drug classes have variable efficacy in treating depression in PD. These results were generally consistent with two other recent meta-analyses of pharmacological treatment of depression in PD, suggesting superiority of TCAs to SSRIs in reducing PD depression symptoms. ${ }^{61,62}$ In contrast to Troeung et al's ${ }^{60}$ findings, Bomasang-Layno et $\mathrm{al}^{59}$ did not find a significant effect of TCAs in the treatment of depression in PD but found that when stratifying SSRI/SNRI treatments versus other pharmacological treatments, the SSRI/SNRI treatment studies showed a significant effect on depressive symptoms in PD. Of note, Troeung et $\mathrm{al}^{60}$ also caution that the nonsignificant treatment effect in SSRIs may be due to the limited number of randomized controlled trials (RCTs) included for analysis $(\mathrm{N}=5)$ and highlighted the need for additional, carefully designed studies. Data from a Department of Veteran's Affairs review on current practice among physicians treating $\mathrm{PD}$ patients shows that $63 \%$ of patients with $\mathrm{PD}$ and depression were taking SSRIs, while only $7 \%$ were taking TCAs. ${ }^{63}$ The US Parkinson Study group conducted a survey among physicians and found that $51 \%$ used SSRIs as first-line treatment for PD depression. ${ }^{64}$ Likely, this practice is based on safety concerns in regards to the use of TCAs, mainly related to their potential for cardiac conduction delay and anticholinergic properties. Finally, a meta-analysis of RCTs on the use of pramipexole, a dopamine agonist, to treat depressive symptoms found that the use of pramipexole significantly improved mood and motivation symptoms. ${ }^{65}$

\section{Behavioral therapies}

Meta-analyses on the effect of behavioral treatments for depression in PD consistently show positive, robust effects. ${ }^{59,60}$ Dobkin et al ${ }^{66}$ used a cognitive behavioral therapy (CBT) approach specifically tailored for Parkinson patients in the treatment group $(\mathrm{N}=41)$, compared to a clinical monitoring control group $(\mathrm{N}=39)$. Those in the CBT group showed greater reduction in depressive symptoms ( $56 \%$ responders, characterized by a greater than $50 \%$ decrease in depressive symptoms) compared to the control group ( $8 \%$ responders). Those in the CBT group also showed greater improvements on measures of anxiety, quality of life, coping, and Parkinson's disease symptom ratings (Unified Parkinson's Disease Rating Scale motor score), and treatment responses were maintained at 1 month posttreatment. To date, the only other RCT (with a nonpharmacological control group) of CBT for the treatment of depression in PD also showed a positive effect of CBT on depressive symptoms, anxiety, and quality of life. ${ }^{67}$ Of note, this study employed telephonedelivery of CBT, used a supportive treatment control group, and only three patients completed treatment in each of the groups. Recent evidence also suggests that group CBT can be effective in treating depression and anxiety symptoms in PD patients. ${ }^{68,69}$

A recent meta-analysis suggested that, in addition to CBT, psychodynamic behavioral therapy for depression in PD is also effective. ${ }^{70}$ The authors of this meta-analysis also suggest that psychodynamic therapy may have larger effects on depressive symptoms than CBT; however, these results may have been biased by the nature of studies included in this metaanalysis. Specifically, most of the CBT studies included in the 
analysis (4/6) compared CBT plus pharmacological treatment to pharmacological treatment alone, whereas most of the psychodynamic therapy studies (4/6) compared psychodynamic treatment to a relatively inactive control group. Importantly, of studies that have compared the use of behavioral therapy plus pharmacological treatment to pharmacological treatment alone, all have found that a combination of behavioral treatment with pharmacological therapy is superior to treatment with a pharmacological agent alone. ${ }^{70}$

\section{Alternative treatments}

Repetitive transcranial magnetic stimulation (rTMS) has received attention for its potential in treating depressive symptoms in PD. ${ }^{71-79}$ A recent meta-analysis of RCTs for the use of rTMS for the treatment of depressive symptoms in PD found rTMS to be superior to sham treatment in reducing depressive symptoms in $\mathrm{PD}$, and to have similar efficacy as SSRIs, with the possible benefit of simultaneous improvement in motor symptoms. ${ }^{80}$ Another meta-analysis found the effect of rTMS on depression in PD to be nonsignificant, based on the two existing RCTs. Based on the current state of the literature, Shirota et al"2 made a "weak recommendation" in favor of high-frequency rTMS of the left dorsolateral prefrontal cortex for the treatment of depressive symptoms in PD.

On the contrary, one of two nonpharmacological treatments for depression in PD in Troeung et al's ${ }^{60}$ meta-analysis that resulted in a larger treatment effect compared to studies of pharmacotherapy was an RCT of OMEGA-III supplementation for depression in PD. ${ }^{60,81}$ After 3 months of supplementation, those receiving OMEGA-III $(\mathrm{N}=14)$ reported decreased depression compared to the placebo group ( $\mathrm{N}=15)$, with $42 \%$ of patients in the OMEGA-III group showing greater than $50 \%$ reduction in depressive symptoms, compared to $6 \%$ in the placebo group. Of note, this study was specifically in PD patients who met criteria for a major depressive episode, and those with cognitive impairments were excluded.

Lastly, case reports have suggested that electroconvulsive therapy (ECT) may be successful in treating severe, medication-refractory depressive ${ }^{82}$ disorders in $\mathrm{PD}$, especially those that result in severe behavior disruption or psychosis, including cases concomitantly treated with deep brain stimulation for treatment of their motoric PD symptoms. ${ }^{83,84}$ Interestingly, ECT has been observed to also improve motor symptoms in these patients. However, the existing literature on ECT in PD patients consists only of case studies; ${ }^{59}$ therefore, more research in the form of RCTs is needed before ECT would be a recommended therapy for psychiatric symptoms in PD.

\section{Anxiety \\ Prevalence and risk factors}

Estimated prevalence of anxiety disorders in PD is approximately $40 \%,{ }^{1,85-87}$ and it is $25 \%-29 \%$ when DSM criteria for anxiety disorders are applied. ${ }^{5,88}$ The most common DSM anxiety disorders to occur in PD are generalized anxiety disorder (GAD), panic disorder, and phobias. ${ }^{5,85,87}$ As in the case of depression in $\mathrm{PD}$, evidence suggests that anxiety symptomology often predates and increases the risk of clinical diagnosis of PD. ${ }^{89-91}$ One study found a direct correlation between severity of anxiety and increased risk for onset of PD. ${ }^{91}$ Studies have consistently found an association between anxiety, younger age of onset of $\mathrm{PD}$, and presence of motor fluctuations. ${ }^{5,85,92,93}$ In addition, there seems to be a link between wearing off of dopaminergic medications and increased anxiety. ${ }^{48,93,94}$

\section{Etiology}

Anxiety in PD may be driven by the psychosocial stress of having the disease, ${ }^{95}$ including social shame related to tremulousness and disability, being dependent on another person, fear of falling, and motor fluctuations. ${ }^{87,95,96}$ However, there is also evidence that a certain proportion of anxiety symptomatology may be due to reduced dopaminergic inhibition of the locus coeruleus, resulting in excess noradrenergic activity. ${ }^{97}$ The same may be true as it pertains to dopaminergic influences on the amygdala in PD. ${ }^{87}$ Anxiety in PD may generally be related to abnormalities in norepinephrine, serotonin, dopamine, and $\gamma$-aminobutyric acid (GABA) neurotransmitters, which have been implicated in the pathogenesis of anxiety ${ }^{98,99}$ and have also been found to be abnormal in PD. ${ }^{4}$ Abnormal functioning of the raphe nucleus and the locus coeruleus, which are both affected by the pattern of Lewy body deposition proposed by Braak staging, ${ }^{100}$ may also play a role in the pathogenesis of anxiety in $\mathrm{PD} .{ }^{87}$

\section{Treatment}

\section{Pharmacological management}

With respect to RCTs that assessed pharmacological effects on anxiety in addition to depression in PD, all SSRI and TCA interventions resulted in large and statistically significant reductions in anxiety, with effect sizes ranging from 0.93 to 1.98 , with the exception of paroxetine. ${ }^{56}$ In addition, atomoxetine was also noted to have a significant effect in lowering anxiety symptoms. ${ }^{101}$ As in the case of depressive symptoms, TCAs showed a superior effect on anxiety than SSRIs. ${ }^{60}$ However, as discussed previously, the use of TCAs clinically is somewhat eschewed owing to their unfavorable side effect profile. 


\section{Behavioral therapies}

Although there have been no RCTs to investigate cognitive behavioral therapy specifically for anxiety disorders in PD, the two trials that investigated CBT for PD depression also collected self-report of anxiety symptoms in these patients. In both studies, CBT, whether delivered in person or via telephone, resulted in significantly decreased anxiety symptoms in PD patients. ${ }^{67,102}$

\section{Alternative treatments}

Marino and Friedman ${ }^{103}$ describe two cases of severe, medication-refractory anxiety in PD that responded positively to ECT. Both patients also showed significant improvement in motor symptoms following ECT therapy. Whether results were maintained in these patients is unknown.

\section{Summary and conclusion}

As summarized in Table 1, depression and anxiety are present in up to $40 \%$ of PD patients and likely relate to the underlying neuropathology of the disease. These psychiatric conditions can present prior to motor manifestation of the disease and impact variables such as level of disability, quality of life, caregiver burden, and mortality. Studies have shown limited support for treatment of PD depression with SSRIs and have suggested higher efficacy of TCAs in the treatment of PD depression; however, most clinicians choose to prescribe SSRIs because of high side effect profiles of TCA. SNRIs such as venlafaxine and the dopamine agonist pramipexole have shown promise in treating depression symptoms in PD. Studies have shown support for both SSRI and TCA treatment of anxiety in $\mathrm{PD}$, and one study showed support for atomoxetine in the treatment of PD anxiety. Evidence suggests that CBT, or a combination of CBT and psychotropic medication, may be most effective in treating mood and anxiety symptoms in PD. Lastly, since depression and anxiety can present very early in the disease process, future studies may want to focus on early intervention strategies for these conditions.

\section{Disclosure}

JBR, THT, and VKH receive salary support from the Michael J.

Fox Foundation for an investigator-initiated research study. THT receives salary support from the Congressionally Directed Medical Research Program / Department of Defense (CDMRP/DOD) for an investigator-initiated randomized controlled trial and salary support from Aker Biomarine for an investigator-initiated randomized controlled trial.
Table I Summary (with literature-based references) of prevalence, risk factors, etiological considerations, and evidence-based treatments for depression and anxiety in Parkinson's disease

\begin{tabular}{|c|c|}
\hline Depression & Anxiety \\
\hline \multicolumn{2}{|l|}{ Prevalence } \\
\hline$\sim 40 \%^{25,27}$ & $\sim 40 \% 1,85-87$ \\
\hline \multicolumn{2}{|l|}{ Risk factors } \\
\hline Akinetic rigid/PIGD motor & Motor fluctuations $s^{5,85,92,93,104}$ \\
\hline subtype ${ }^{25,34-36}$ & Younger onset ${ }^{87,104}$ \\
\hline \multicolumn{2}{|l|}{ Motor fluctuations $s^{39,104}$} \\
\hline \multicolumn{2}{|l|}{ Younger disease onset ${ }^{38,39,41}$} \\
\hline \multicolumn{2}{|c|}{ Right-sided motor asymmetry ${ }^{41-43}$} \\
\hline \multicolumn{2}{|c|}{ Female sex ${ }^{45}$} \\
\hline \multicolumn{2}{|c|}{ History of premorbid depression ${ }^{45}$} \\
\hline \multicolumn{2}{|c|}{ Family history of depression ${ }^{45}$} \\
\hline \multicolumn{2}{|c|}{ Worse disability/poor cognition ${ }^{45}$} \\
\hline \multicolumn{2}{|c|}{ Neurobiological components } \\
\hline $\begin{array}{l}\text { Mesolimbic dopaminergic } \\
\text { dysfunction }\end{array}$ & $\begin{array}{l}\text { Disinhibition/dysfunction of } \\
\text { amygdala }\end{array}$ \\
\hline Mesocortical dopaminergic & Disinhibition/dysfunction of locus \\
\hline dysfunction & coeruleus $^{87,97}$ \\
\hline Serotonergic dysfunction ${ }^{47}$ & Dysfunction of raphe nucleus ${ }^{87}$ \\
\hline \multirow[t]{4}{*}{ Neuroinflammation ${ }^{52,53}$} & Abnormalities in norepinephrine, \\
\hline & serotonin, dopamine, and \\
\hline & $\gamma$-aminobutyric acid (GABA) \\
\hline & neurotransmitters $\mathrm{s}^{4,87}$ \\
\hline \multicolumn{2}{|l|}{ Psychosocial components } \\
\hline \multirow{5}{*}{$\begin{array}{l}\text { Adjustment to chronic } \\
\text { illness/disability }\end{array}$} & Adjustment to chronic illness/ \\
\hline & disability 87,95 \\
\hline & Social shame ${ }^{95}$ \\
\hline & Motor fluctuations ${ }^{85}$ \\
\hline & Fear of falling 25 \\
\hline \multicolumn{2}{|c|}{ Pharmacologic treatments } \\
\hline$\left.S S R\right|^{59,60}$ & $\left.\operatorname{SSR}\right|^{56,60}$ \\
\hline SNRI ${ }^{54,59}$ & $\mathrm{TCA}^{56,60}$ \\
\hline $\mathrm{TCA}^{59,60}$ & Atomoxetine $e^{101}$ \\
\hline \multicolumn{2}{|l|}{ Pramipexole ${ }^{65}$} \\
\hline \multicolumn{2}{|c|}{ Nonpharmacological treatments } \\
\hline $\mathrm{CBT}^{19,20}$ & $\mathrm{CBT}^{19,20}$ \\
\hline Omega-IIII20,83 & $\mathrm{ECT}^{103}$ \\
\hline \multicolumn{2}{|l|}{ rTMS $^{59,72,80}$} \\
\hline $\mathrm{ECT}^{82-84}$ & \\
\hline
\end{tabular}

Abbreviations: PIGD, postural instability/gait disorder; SSRI, selective serotonin reuptake inhibitor; SNRI, serotonin-norepinephrine reuptake inhibitor; TCA, tricyclic antidepressant; CBT, cognitive behavioral therapy; rTMS, repetitive transcranial magnetic stimulation; $\mathrm{ECT}$, electroconvulsive therapy.

VKH has received research grant support from the National Institute of Health, Accorda Pharmaceuticals, Abbvie, Biotie Therapies, and the Barmore fund.

\section{References}

1. Nuti A, Ceravolo R, Piccinni A, et al. Psychiatric comorbidity in a population of Parkinson's disease patients. Eur J Neurol. 2004;11(5): 315-320.

2. Stein MB, Heuser IJ, Juncos JL, Uhde TW. Anxiety disorders in patients with Parkinson's disease. Am J Psychiatry. 1990;147(2):217-220. 
3. Chinaglia G, Alvarez FJ, Probst A, Palacios J. Mesostriatal and mesolimbic dopamine uptake binding sites are reduced in Parkinson's disease and progressive supranuclear palsy: a quantitative autoradiographic study using [3H]mazindol. Neuroscience. 1992;49(2): 317-327.

4. Mayeux R, Stern Y, Williams JB, Cote L, Frantz A, Dyrenfurth I. Clinical and biochemical features of depression in Parkinson's disease. Am J Psychiatry. 1986;143(6):756-759.

5. Dissanayaka NN, Sellbach A, Matheson S, et al. Anxiety disorders in Parkinson's disease: prevalence and risk factors. Mov Disord. 2010;25(7):838-845.

6. Duncan GW, Khoo TK, Yarnall AJ, et al. Health-related quality of life in early Parkinson's disease: the impact of nonmotor symptoms. Mov Disord. 2014;29(2):195-202.

7. Visser M, Van Rooden S, Verbaan D, Marinus J, Stiggelbout A, Van Hilten J. A comprehensive model of health-related quality of life in Parkinson's disease. J Neurol. 2008;255(10):1580-1587.

8. Wu Y, Guo XY, Wei QQ, et al. Non-motor symptoms and quality of life in tremor dominant vs postural instability gait disorder Parkinson's disease patients. Acta Neurol Scand. 2015. Epub July 20, 2015.

9. Yamanishi T, Tachibana H, Oguru M, et al. Anxiety and depression in patients with Parkinson's disease. Intern Med. 2013;52(5):539-545.

10. Müller B, Assmus J, Herlofson K, Larsen JP, Tysnes OB. Importance of motor vs. non-motor symptoms for health-related quality of life in early Parkinson's disease. Parkinsonism Relat Disord. 2013;19(11):1027-1032.

11. Weintraub D, Moberg PJ, Duda JE, Katz IR, Stern MB. Effect of psychiatric and other nonmotor symptoms on disability in Parkinson's disease. J Am Geriatr Soc. 2004;52(5):784-788.

12. Hinnell C, Hurt CS, Landau S, Brown RG, Samuel M. Nonmotor versus motor symptoms: how much do they matter to health status in Parkinson's disease? Mov Disord. 2012;27(2):236-241.

13. Quelhas R, Costa M. Anxiety, depression, and quality of life in Parkinson's disease. J Neuropsychiatry Clin Neurosci. 2009;21(4):413-419.

14. Schrag A, Hovris A, Morley D, Quinn N, Jahanshahi M. Caregiverburden in Parkinson's disease is closely associated with psychiatric symptoms, falls, and disability. Parkinsonism Relat Disord. 2006;12(1):35-41.

15. Martinez-Martin P, Rodriguez-Blazquez C, Forjaz MJ, et al. Neuropsychiatric symptoms and caregiver's burden in Parkinson's disease. Parkinsonism Relat Disord. 2015;21(6):629-634.

16. Leiknes I, Tysnes OB, Aarsland D, Larsen J. Caregiver distress associated with neuropsychiatric problems in patients with early Parkinson's disease: the Norwegian ParkWest study. Acta Neurol Scand. 2010;122(6):418-424.

17. Meara J, Mitchelmore E, Hobson P. Use of the GDS-15 geriatric depression scale as a screening instrument for depressive symptomatology in patients with Parkinson's disease and their carers in the community. Age Ageing. 1999;28(1):35-38.

18. Brown R, MacCarthy B, Gotham AM, Der G, Marsden C. Depression and disability in Parkinson's disease: a follow-up of 132 cases. Psychol Med. 1988;18(1):49-55.

19. Starkstein SE, Mayberg HS, Leiguarda R, Preziosi TJ, Robinson RG. A prospective longitudinal study of depression, cognitive decline, and physical impairments in patients with Parkinson's disease. J Neurol Neurosurg Psychiatry. 1992;55(5):377-382.

20. Pontone GM, Bakker CC, Chen S, et al. The longitudinal impact of depression on disability in Parkinson disease. Int J Geriatr Psychiatry. 2015. Epub August 18, 2015.

21. Ravina B, Camicioli R, Como P, et al. The impact of depressive symptoms in early Parkinson disease. Neurology. 2007;69(4):342-347.

22. Jenkinson C, Fitzpatrick R, Peto V, Greenhall R, Hyman N. The PDQ-8: development and validation of a short-form Parkinson's disease questionnaire. Psychol Health. 1997;12(6):805-814.

23. Hughes T, Ross H, Mindham R, Spokes E. Mortality in Parkinson's disease and its association with dementia and depression. Acta Neurol Scand. 2004;110(2):118-123.
24. Vetrano DL, Pisciotta MS, Monaco MRL, et al. Association of depressive symptoms with circadian blood pressure alterations in Parkinson's disease. J Neurol. 2015;262(11):2564-2571.

25. Reijnders JS, Ehrt U, Weber WE, Aarsland D, Leentjens AF. A systematic review of prevalence studies of depression in Parkinson's disease. Mov Disord. 2008;23(2):183-189.

26. Lehrner J, Moser D, Klug S, et al. Subjective memory complaints, depressive symptoms and cognition in Parkinson's disease patients. Eur J Neurol. 2014;21(10):1276-1284, e77.

27. Slaughter JR, Slaughter KA, Nichols D, Holmes SE, Martens MP. Prevalence, clinical manifestations, etiology, and treatment of depression in Parkinson's disease. J Neuropsychiatry Clin Neurosci. 2001;13(2):187-196.

28. Stenager EN, Wermuth L, Stenager E, Boldsen J. Suicide in patients with Parkinson's disease. An epidemiological study. Acta Psychiatr Scand. 1994;90(1):70-72.

29. Kostic VS, Pekmezovic T, Tomic A, et al. Suicide and suicidal ideation in Parkinson's disease. J Neurol Sci. 2010;289(1-2):40-43.

30. Myslobodsky M, Lalonde FM, Hicks L. Are patients with Parkinson's disease suicidal? J Geriatr Psychiatry Neurol. 2001;14(3):120-124.

31. Weintraub D, Simuni T, Caspell-Garcia C, et al. Cognitive performance and neuropsychiatric symptoms in early, untreated Parkinson's disease. Mov Disord. 2015;30(7):919-927.

32. Alonso A, Rodríguez LG, Logroscino G, Hernán MA. Use of antidepressants and the risk of Parkinson's disease: a prospective study. J Neurol Neurosurg Psychiatry. 2009;80(6):671-674.

33. Gustafsson H, Nordstrom A, Nordstrom P. Depression and subsequent risk of Parkinson disease: a nationwide cohort study. Neurology. 2015;84(24):2422-2429.

34. Poletti M, Frosini D, Pagni C, et al. The association between motor subtypes and alexithymia in de novo Parkinson's disease. J Neurol. 2011;258(6):1042-1045.

35. Starkstein SE, Petracca G, Chemerinski E, et al. Depression in classic versus akinetic-rigid Parkinson's disease. Mov Disord. 1998;13(1): 29-33.

36. Factor SA, Steenland NK, Higgins DS, et al. Postural instability/gait disturbance in Parkinson's disease has distinct subtypes: an exploratory analysis. J Neurol Neurosurg Psychiatry. 2011;82(5):564-568.

37. Lewis S, Foltynie T, Blackwell A, Robbins T, Owen A, Barker R. Heterogeneity of Parkinson's disease in the early clinical stages using a data driven approach. J Neurol Neurosurg Psychiatry. 2005;76(3):343-348.

38. Reijnders JS, Ehrt U, Lousberg R, Aarsland D, Leentjens AF. The association between motor subtypes and psychopathology in Parkinson's disease. Parkinsonism Relat Disord. 2009;15(5):379-382.

39. Starkstein SE, Berthier M, Bolduc PL, Preziosi TJ, Robinson R. Depression in patients with early versus late onset of Parkinson's disease. Neurology. 1989;39(11):1441-1445.

40. Dissanayaka NN, Sellbach A, Silburn PA, O’Sullivan JD, Marsh R, Mellick GD. Factors associated with depression in Parkinson's disease. J Affect Disord. 2011;132(1-2):82-88.

41. Cole SA, Woodard JL, Juncos JL, Kogos JL, Youngstrom EA, Watts RL. Depression and disability in Parkinson's disease. J Neuropsychiatry Clin Neurosci. 1995;8(1):20-25.

42. Leentjens A, Lousberg R, Verhey F. Markers for depression in Parkinson's disease. Acta Psychiatr Scand. 2002;106(3):196-201.

43. Starkstein SE, Preziosi TJ, Bolduc PL, Robinson RG. Depression in Parkinson's disease. J Nerv Ment Dis. 1990;178(1):27-31.

44. Leentjens AF, Verhey FR, Luijckx GJ, Troost J. The validity of the Beck Depression Inventory as a screening and diagnostic instrument for depression in patients with Parkinson's disease. Mov Disord. 2000;15(6):1221-1224.

45. Leentjens AF, Moonen AJ, Dujardin K, et al. Modeling depression in Parkinson disease: disease-specific and nonspecific risk factors. Neurology. 2013;81(12):1036-1043.

46. Mayeux R. The "serotonin hypothesis" for depression in Parkinson's disease. Adv Neurol. 1990;53:163-166. 
47. Zgaljardic DJ, Borod JC, Foldi NS, Mattis P. A review of the cognitive and behavioral sequelae of Parkinson's disease: relationship to frontostriatal circuitry. Cogn Behav Neurol. 2003;16(4):193-210.

48. Maricle RA, Nutt JG, Valentine RJ, Carter JH. Dose-response relationship of levodopa with mood and anxiety in fluctuating Parkinson's disease: a double-blind, placebo-controlled study. Neurology. 1995;45(9):1757-1760.

49. Friedman A, Friedman Y, Dremencov E, Yadid G. VTA dopamine neuron bursting is altered in an animal model of depression and corrected by desipramine. J Mol Neurosci. 2008;34(3):201-209.

50. Nestler EJ, Carlezon WA. The mesolimbic dopamine reward circuit in depression. Biol Psychiatry. 2006;59(12):1151-1159.

51. Mayberg HS. Limbic-cortical dysregulation: a proposed model of depression. J Neuropsychiatry Clin Neurosci. 1997;9(3):471-481.

52. Lindqvist D, Hall S, Surova Y, et al. Cerebrospinal fluid inflammatory markers in Parkinson's disease - associations with depression, fatigue, and cognitive impairment. Brain Behav Immun. 2013;33: 183-189.

53. Menza M, Dobkin RD, Marin H, et al. The role of inflammatory cytokines in cognition and other non-motor symptoms of Parkinson's disease. Psychosomatics. 2010;51(6):474-479.

54. Richard IH, McDermott MP, Kurlan R, et al. A randomized, doubleblind, placebo-controlled trial of antidepressants in Parkinson disease. Neurology. 2012;78(16):1229-1236.

55. Hamilton M, Guy W. Hamilton depression scale. In: Guy W, editor. ECDEU Assessment Manual for Psychopharmacology. Rockville, MD National Institute of Mental Health; 1976:179-192.

56. Menza M, Dobkin RD, Marin H, et al. A controlled trial of antidepressants in patients with Parkinson disease and depression. Neurology. 2009;72(10):886-892.

57. Leentjens A, Vreeling F, Luijckx GJ, Verhey F. SSRIs in the treatment of depression in Parkinson's disease. Int J Geriatr Psychiatry. 2003;18(6):552-554.

58. Wermuth L, Sørensen P, Timm S, et al. Depression in idiopathic Parkinson's disease treated with citalopram: a placebo-controlled trial. Nord J Psychiatry. 1998;52(2):163-169.

59. Bomasang-Layno E, Fadlon I, Murray AN, Himelhoch S. Antidepressive treatments for Parkinson's disease: a systematic review and metaanalysis. Parkinsonism Relat Disord. 2015;21(8):833-842.

60. Troeung L, Egan SJ, Gasson N. A meta-analysis of randomised placebocontrolled treatment trials for depression and anxiety in Parkinson's disease. PLoS One. 2013;8(11):e79510.

61. Rocha FL, Murad MG, Stumpf BP, Hara C, Fuzikawa C. Antidepressants for depression in Parkinson's disease: systematic review and meta-analysis. J Psychopharmacol. 2013;27(5):417-423.

62. Skapinakis P, Bakola E, Salanti G, Lewis G, Kyritsis AP, Mavreas V. Efficacy and acceptability of selective serotonin reuptake inhibitors for the treatment of depression in Parkinson's disease: a systematic review and meta-analysis of randomized controlled trials. BMC Neurol. 2010;10(1):49.

63. Chen P, Kales HC, Weintraub D, Blow FC, Jiang L, Mellow AM. Antidepressant treatment of veterans with Parkinson's disease and depression: analysis of a national sample. J Geriatr Psychiatry Neurol. 2007;20(3):161-165.

64. Richard IH, Kurlan R. A survey of antidepressant drug use in Parkinson's disease. Neurology. 1997;49(4):1168-1170.

65. Leentjens AF, Koester J, Fruh B, Shephard DTS, Barone P, Houben JJ. The effect of pramipexole on mood and motivational symptoms in Parkinson's disease: a meta-analysis of placebo-controlled studies. Clin Ther. 2009;31(1):89-98.

66. Dobkin RD, Menza M, Bienfait KL. CBT for the treatment of depression in Parkinson's disease: a promising nonpharmacological approach. Expert Rev Neurother. 2008;8(1):27-35.

67. Veazey C, Cook K, Stanley M, Lai E, Kunik M. Telephoneadministered cognitive behavioral therapy: a case study of anxiety and depression in Parkinson's disease. J Clin Psychol Med Settings. 2009;16(3):243-253
68. Troeung L, Egan SJ, Gasson N. A waitlist-controlled trial of group cognitive behavioural therapy for depression and anxiety in Parkinson's disease. BMC Psychiatry. 2014;14(1):19.

69. Berardelli I, Pasquini M, Bloise M, et al. CBT Group intervention for depression, anxiety, and motor symptoms in Parkinson's disease: preliminary findings. Int J Cogn Ther. 2015;8(1):11-20.

70. Xie CL, Wang X-D, Chen J, et al. A systematic review and meta-analysis of cognitive behavioral and psychodynamic therapy for depression in Parkinson's disease patients. Neurol Sci. 2015;36(6):833-843.

71. Oguro H, Nakagawa T, Mitaki S, Ishihara M, Onoda K. Randomized trial of repetitive transcranial magnetic stimulation for apathy and depression in Parkinson's disease. J Neurol Neurophysiol. 2014;5(242):2.

72. Shirota Y, Hamada M, Ugawa Y. Clinical applications of rTMS in Parkinson's disease. In: Therapeutic rTMS in Neurology. New York, NY: Springer; 2016:129-145.

73. Boggio PS, Fregni F, Bermpohl F, et al. Effect of repetitive TMS and fluoxetine on cognitive function in patients with Parkinson's disease and concurrent depression. Mov Disord. 2005;20(9):1178-1184.

74. Maruo T, Hosomi K, Shimokawa T, et al. High-frequency repetitive transcranial magnetic stimulation over the primary foot motor area in Parkinson's disease. Brain Stimul. 2013;6(6):884-891.

75. Chen R. Repetitive transcranial magnetic stimulation as treatment for depression in Parkinson's disease. Mov Disord. 2010;25(14):2272-2273.

76. Dragaševic N, Potrebić A, Damjanović A, Stefanova E, Kostić VS. Therapeutic efficacy of bilateral prefrontal slow repetitive transcranial magnetic stimulation in depressed patients with Parkinson's disease: an open study. Mov Disord. 2002;17(3):528-532.

77. Epstein CM, Evatt ML, Funk A, et al. An open study of repetitive transcranial magnetic stimulation in treatment-resistant depression with Parkinson's disease. Clin Neurophysiol. 2007;118(10):2189-2194.

78. Fregni F, Santos C, Myczkowski M, et al. Repetitive transcranial magnetic stimulation is as effective as fluoxetine in the treatment of depression in patients with Parkinson's disease. J Neurol Neurosurg Psychiatry. 2004;75(8):1171-1174.

79. Kormos TC. Efficacy of rTMS in the treatment of co-morbid anxiety in depressed patients with Parkinson's disease. Mov Disord. 2007;22(12):1836.

80. Xie CL, Chen J, Wang XD, et al. Repetitive transcranial magnetic stimulation (rTMS) for the treatment of depression in Parkinson disease: a meta-analysis of randomized controlled clinical trials. Neurol Sci. 2015;36(10):1751-1761.

81. Moralez da Silva T, Munhoz RP, Alvarez C, et al. Depression in Parkinson's disease: a double-blind, randomized, placebo-controlled pilot study of omega-3 fatty-acid supplementation. J Affect Disord. 2008;111(2-3):351-359.

82. Moellentine C, Rummans T, Ahlskog JE, et al. Effectiveness of ECT in patients with parkinsonism. $J$ Neuropsychiatry Clin Neurosci. 1998;10(2):187-193.

83. Chou KL, Hurtig HI, Jaggi JL, Baltuch GH, Pelchat RJ, Weintraub D. Electroconvulsive therapy for depression in a Parkinson's disease patient with bilateral subthalamic nucleus deep brain stimulators. Parkinsonism Relat Disord. 2005;11(6):403-406.

84. Nasr S, Murillo A, Katariwala N, Mothkur V, Wendt B. Case report of electroconvulsive therapy in a patient with Parkinson disease concomitant with deep brain stimulation. J ECT. 2011;27(1):89-90.

85. Pontone GM, Williams JR, Anderson KE, et al. Prevalence of anxiety disorders and anxiety subtypes in patients with Parkinson's disease. Mov Disord. 2009;24(9):1333-1338.

86. Rutten S, Ghielen I, Vriend C, et al. Anxiety in Parkinson's disease: symptom dimensions and overlap with depression and autonomic failure. Parkinsonism Relat Disord. 2015;21(3):189-193.

87. Dissanayaka NN, White E, O'Sullivan JD, Marsh R, Pachana NA, Byrne GJ. The clinical spectrum of anxiety in Parkinson's disease. Mov Disord. 2014;29(8):967-975.

88. Menza MA, Robertson-Hoffman DE, Bonapace AS. Parkinson's disease and anxiety: comorbidity with depression. Biol Psychiatry. 1993;34(7):465-470. 
89. Shiba M, Bower JH, Maraganore DM, et al. Anxiety disorders and depressive disorders preceding Parkinson's disease: a case-control study. Mov Disord. 2000;15(4):669-677.

90. Weisskopf MG, Chen H, Schwarzschild MA, Kawachi I, Ascherio A. Prospective study of phobic anxiety and risk of Parkinson's disease. Mov Disord. 2003;18(6):646-651.

91. Lin CH, Lin JW, Liu YC, Chang CH, Wu RM. Risk of Parkinson's disease following anxiety disorders: a nationwide population-based cohort study. Eur J Neurol. 2015;22(9):1280-1287.

92. Burn DJ, Landau S, Hindle JV, et al. Parkinson's disease motor subtypes and mood. Mov Disord. 2012;27(3):379-386.

93. Leentjens AF, Dujardin K, Marsh L, Martinez-Martin P, Richard IH, Starkstein SE. Anxiety and motor fluctuations in Parkinson's disease: a cross-sectional observational study. Parkinsonism Relat Disord. 2012;18(10):1084-1088.

94. Witjas T, Kaphan E, Azulay J, et al. Nonmotor fluctuations in Parkinson's disease: frequent and disabling. Neurology. 2002;59(3):408-413.

95. Macht M, Schwarz R, Ellgring H. Patterns of psychological problems in Parkinson's disease. Acta Neurol Scand. 2005;111(2):95-101.

96. Rahman S, Griffin HJ, Quinn NP, Jahanshahi M. On the nature of fear of falling in Parkinson's disease. Behav Neurol. 2011;24(3): 219-228.
97. Iruela LM, Ibañez-Rojo V, Palanca I, Caballero L. Anxiety disorders and Parkinson's disease. Am J Psychiatry. 1992;149(5):719-720.

98. Heninger GR, Charney DS. Monoamine receptor systems and anxiety disorders. Psychiatr Clin North Am. 1988;11(2):309-326.

99. Nutt D, Lawson C. Panic attacks. A neurochemical overview of models and mechanisms. Br J Psychiatry. 1992;160(2):165-178.

100. Braak H, Ghebremedhin E, Rub U, Bratzke H, Del Tredici K. Stages in the development of Parkinson's disease-related pathology. Cell Tissue Res. 2004;318(1):121-134.

101. Weintraub D, Mavandadi S, Mamikonyan E, et al. Atomoxetine for depression and other neuropsychiatric symptoms in Parkinson disease. Neurology. 2010;75(5):448-455.

102. Dobkin RD, Menza M, Allen LA, et al. Cognitive-behavioral therapy for depression in Parkinson's disease: a randomized, controlled trial. Am J Psychiatry. 2011;168(10):1066-1074.

103. Marino L, Friedman JH. Letter to the editor: successful use of electroconvulsive therapy for refractory anxiety in Parkinson's disease. Int J Neurosci. 2012;123(1):70-71.

104. Sagna A, Gallo JJ, Pontone GM. Systematic review of factors associated with depression and anxiety disorders among older adults with Parkinson's disease. Parkinsonism Relat Disord. 2014;20(7): 708-715.
Journal of Parkinsonism \& Restless Legs Syndrome

\section{Publish your work in this journal}

Journal of Parkinsonism and Restless Legs Syndrome is an online, open access, peer-reviewed journal. The journal publishes review articles, historical reviews, original research articles, case reports, letters to the editor, clinical teaching cases, neuroradiology highlights, neuropathology highlights, neuropsychiatry highlights, autobiographies, conference

\section{Dovepress}

proceedings, abstracts and book reviews. The manuscript management system is completely online and includes a very quick and fair peerreview system, which is all easy to use. Visit http://www.dovepress.com testimonials.php to read real quotes from published authors. 